Gut, 1968, 9, 521-526

\title{
Studies of intestinal fermentation in ulcerative colitis
}

\author{
R. D. MONTGOMERY, A. C. FRAZER, CATHRYN HOOD, \\ J. M. GOODHART, M. R. HOLLAND, AND R. SCHNEIDER
}

From the Metabolic Unit, East Birmingham Hospital, Birmingham

Evidence of impaired function of the small bowel has been reported in ulcerative colitis (Salem and Truelove, 1965). A preliminary report of metabolic studies in three patients (Frazer, Hood, Montgomery, Davies, Schneider, Carter, and Goodhart, 1966) showed that severe ulcerative colitis might be accompanied not only by steatorrhoea but by increased bowel excretion of lactic acid and volatile fatty acids. We report here further studies on these fermentation products in colitis, and their relation to abnormalities of small bowel function and the effects of alterations in the dietary intake of carbohydrate.

\section{CASES}

Twenty-three patients were studied; 16 had total proctocolitis, three had proctocolitis distal to the splenic flexure, and four had proctitis with a radiologically normal colon. The duration of disease ranged from four weeks to 12 years, but the majority were investigated within a year of onset. All were in an active phase with troublesome symptoms and about half of the patients with total involvement were very severely ill. Studies were also made of the ileal fluid of four cases at varying periods after proctocolectomy and ileostomy.

\section{METHODS}

Faecal long-chain fatty acids ('faecal fat') were estimated in continuous 24-hour collections by the method of van de Kamer, ten Bokkel Huinink, and Weyers (1949), and calculated as stearic acid. Volatile fatty acids (VFA) were estimated by titration against tetraethyl ammonium hydroxide after steam distillation and expressed as acetic acid (normal values, less than $1 \mathrm{~g}$ per 24 hours.) Faecal lactic acid was estimated by the method of Friedemann and Graeser (1933) (normal values, less than $40 \mathrm{mg}$ per 24 hours). The figures given in this paper for faecal fat, VFA, and lactic acid refer to the means of at least four 24-hour collections. In the xylose excretion test, split urine collections were made after a $5 \mathrm{~g}$ oral dose, as described by Sammons, Morgan, Frazer, Montgomery, Philip, and Phillips (1967). Mucosal enzymes were assayed by the method of Auricchio, Rubino, Tosi, Semenza, Landolt, Kistler, and Prader (1963), and expressed per gram wet weight of tissue.

\section{RESULTS}

The evidence of small bowel disorder is summarized in Table I. The mean daily fat excretion exceeded $6 \mathrm{~g}$ in nine of the 16 cases with total involvement $(56 \%)$, and in seven of those it exceeded $7 \mathrm{~g}$ per day. The xylose excretion test showed reduced urinary five-hour excretion in $30 \%$ of all cases, and in $35 \%$ there was a reduced two-hour excretion which may be a more delicate index of small bowel disorder (Sammons et al, 1967). The serum folate activity was reduced below $2.5 \mathrm{~m} \mu \mathrm{g} / \mathrm{ml}$ in $26 \%$. Abnormal Schilling tests were found in two out of five cases, both with severe symptoms and steatorrhoea, the figures for urinary recovery being 5.2 and $9.7 \%$ in 48 hours.

TABLE I

EVIDENCE OF SMALL BOWEL DISORDER IN ACTIVE ULCERATIVE COLITIS

\begin{tabular}{lllr}
$\begin{array}{l}\text { Proctitis } \\
(4 \text { cases })\end{array}$ & $\begin{array}{l}\text { Distal } \\
\text { Colitis } \\
(3 \text { cases })\end{array}$ & $\begin{array}{l}\text { Total } \\
\text { Colitis } \\
(16 \text { cases })\end{array}$ & $\begin{array}{r}\text { All } \\
(\%)\end{array}$ \\
\hline 0 & 0 & 9 & 39 \\
2 & 2 & 3 & 30 \\
1 & 1 & 4 & 26 \\
- & - & 2 & 9
\end{tabular}

\begin{tabular}{lllrl}
\hline Steatorrhoea (mean stool fat $>6 \mathrm{~g}$ per day) & 0 & 0 & 9 & 39 \\
Abnormal xylose excretion test $(<29 \%$ in $5 \mathrm{hr})$ & 2 & 2 & 3 & 30 \\
Reduced serum folate $(<2.5 \mathrm{~m} / \mu \mathrm{g}$ per ml) & 1 & 1 & 4 & 26 \\
Partial villous atrophy of jejunum & - & 2 & 9
\end{tabular}

'Biopsy performed in 11 cases with total colitis. 
JEJUNAL BIOPSIES Jejunal biopsy was performed on 11 patients, all with total colitis whose symptoms were moderate or severe. Minor villous abnormalities (category II of Salem and Truelove, 1965) were present in six cases and partial villous atrophy (category III) in two cases.

In two cases no lactase activity could be detected in the biopsy specimen. One of these had normal activity of sucrase and maltase and normal histology. The other had low sucrase and maltase levels (2.3 and 5.5 international units respectively) and partial villous atrophy. In other cases the lactase activity ranged from 1.7 to 18 international units.

EXCRETION OF VOLATILE FATTY ACIDS AND LACTIC ACID. Initially after admission the mean 24-hour stool content of lactic acid was increased in 15 out of 18 cases, four patients having a daily excretion in excess of $1 \mathrm{~g}$. The figures correlated significantly with stool volume (Fig. 1). The daily VFA excretion was abnormally increased in 15 out of 18 cases. Although the three highest lactic acid figures were found in patients with steatorrhoea exceeding $7 \mathrm{~g}$ per day, there was no clear overall correlation between the excretion of long-chain fats, VFA, or lactic acid; nor was VFA excretion related to stool volume. One patient whose lactic acid excretion rose to $2.3 \mathrm{~g}$ per day had a VFA stool content of only $1 \cdot 2 \mathrm{~g}$, whereas the highest excretion of VFA (10 $\mathrm{g}$ per day) was found in a patient with a lactic acid content of $145 \mathrm{mg}$ per day. However, there was correlation not only with the anatomical extent of

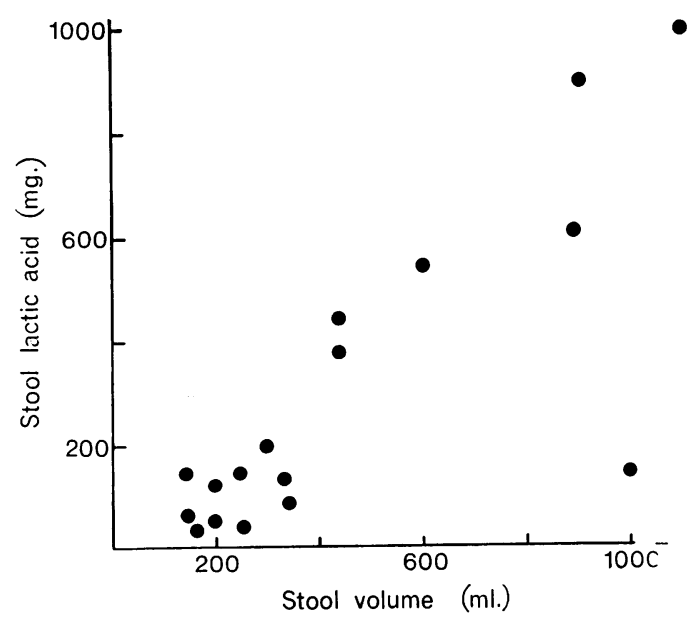

FIG. 1. The relation of stool lactic acid excretion to stool volume. Mean 24-hour figures in 18 cases of ulcerative colitis on first admission. the disease but with the clinical severity. In Table II, cases are divided clinically into mild, moderate, and severe colitis, and it is evident that abnormalities of stool fat, VFA, and lactic acid are all maximal in the severe group.

Both the cases with jejunal hypolactasia had steatorrhoea $(7 \cdot 1 \mathrm{~g}$ and $12.0 \mathrm{~g}$ per day respectively) and high excretion of VFA and lactic acid. The other patient with partial villous atrophy but with normal jejunal enzyme activity excreted $7 \cdot 2 \mathrm{~g}$ fat and $1.5 \mathrm{~g}$ VFA but only $40 \mathrm{mg}$ of lactic acid.

\section{TABLE II}

EXCRETION OF FAT, VFA, AND LACTIC ACID RELATED TO CLINICAL SEVERITY OF COLITIS ${ }^{1}$

\begin{tabular}{llll} 
Severity of Colitis & Fat & VFA & Lactic Acid \\
\hline Mild & 3.6 & 0.30 & 0.04 \\
Moderate & 3.5 & $1 \cdot 3$ & 0.13 \\
Severe & 6.9 & 3.5 & 0.66
\end{tabular}

${ }^{1}$ Results in mean grams per day

ILEOSTOMY FLUID The results in four ileostomy patients are shown in Table III. In the immediate postoperative period with little or no oral intake, all fatty constituents and lactic acid were present in only small amounts. The two patients studied two to four weeks after operation, on a light diet with a high proportion of milk and its products, showed 'steatorrhoea' and higher lactic acid excretion than is found in normal stool.

The last case, a healthy ileostomy subject on a mixed home diet, was repeatedly studied and excreted 450-1,000 $\mathrm{mg}$ of lactic acid and 2.6-4 $\mathrm{g}$ VFA per day, with normal long-chain fat.

EFFECTS OF VARIATION IN DIETARY CARBOHYDRATES Dietary studies were made on 12 patients, all with total colitis and raised stool lactic acid content. In four of these with profuse diarrhoea and lactic - acid figures over $\mathbf{4 0 0} \mathrm{mg}$ per day, almost complete removal of sugars and starch from the diet resulted in clinical improvement, with steady reduction in stool volume and a corresponding fall in stool lactic acid. The VFA excretion fell slowly and irregularly but finally reached normal levels. Three of these cases have been reported previously (Frazer et al, 1966). One of them (case 1) was readmitted with an acute relapse after two years' complete clinical remission. During this time his diet had been progressively relaxed. On readmission his stool volume was of the order of $700 \mathrm{ml}$ per day and stool lactic acid approximately $700 \mathrm{mg}$ per day, and sigmoidoscopy showed intense colitis with ulceration and contact bleeding. He again showed steady improvement in stool volume and stool constituents 
TABLE III

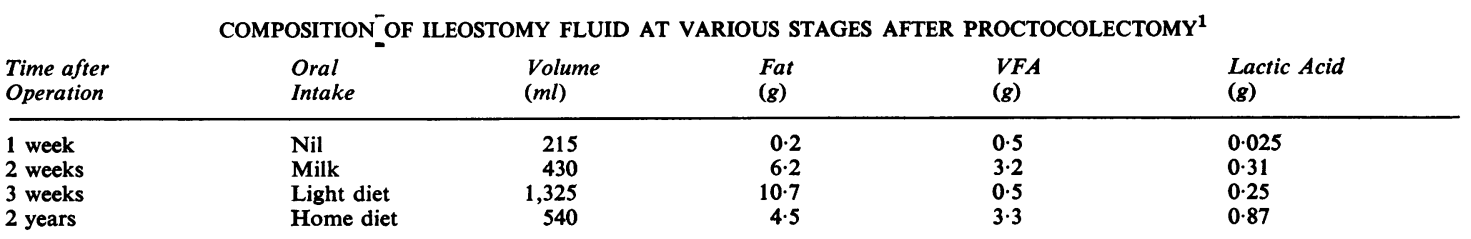

124-hour values

over a period of 10 days on the same dietary restriction, and this was accompanied by clinical remission and rapid healing of the rectosigmoid ulceration.

The fourth patient in this group (case 12) was a 37-year-old man with severe colitis of six weeks' duration, with blood loss, abdominal pains, and anorexia. There was partial villous atrophy of the small bowel (lactase activity of biopsy specimen 2.6 units). His excellent response to diet is indicated in Figure 2.

All these four patients were on steady oral doses of sulphasalazine throughout the period of study. Two of them had had limited courses of prednisone (one orally and one by enema) before the study, without improvement. The condition of all of them had been stationary or slowly deteriorating. Although their improvement on a restricted diet could have been coincidental, it was clinically impressive.

In three other cases the main symptom was frequency of stools, with loss of blood and mucus, but little or no increase in volume $(150-250 \mathrm{ml}$ per day) and with lactic acid figures less than $250 \mathrm{mg}$ per day. In these the same dietary restriction produced a fall in lactic acid with no significant change in volatile fatty acids. Although clinical improvement eventually followed there was no convincing evidence that this was influenced by the diet.

In the remaining five cases the diet had no beneficial effect over a period of at least two weeks. In three of these the initial lactic acid figure was less than $200 \mathrm{mg}$ per day. In these five patients the diet was further restricted for short periods by the removal of cellulose, with no effect except in case 20, who showed an unusual response. With removal of sugars and starch the stool lactic acid in this patient ranged up to $1 \mathrm{~g}$ per day. On progressive reintroduction of sugars the figures rose to $2 \mathrm{~g}$. When cellulose was withdrawn the lactic acid level fell dramatically to $70 \mathrm{mg}$ and it rose again to over $200 \mathrm{mg}$ on two occasions when cellulose was briefly re-introduced (Fig. 3). Although the rise on these occasions was smaller than previously, the amount of dietary cellulose re-introduced was less, and for shorter periods. Repeated stool examination in this patient revealed strains of $E$. coli and of Clostridium welchii. No fermentation of cellulose could

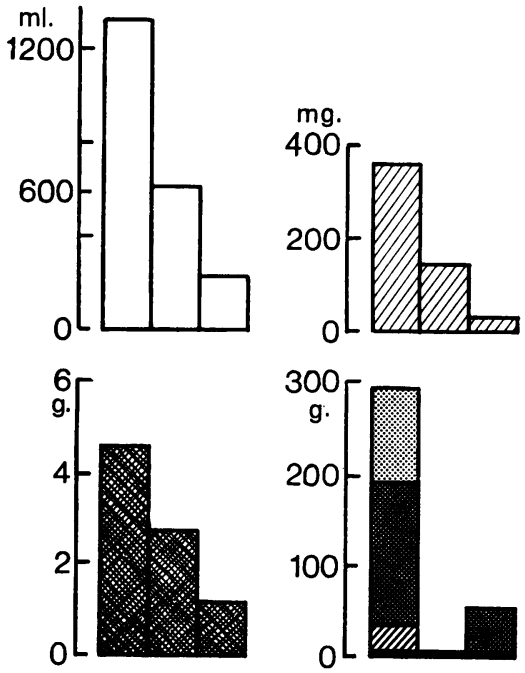

Stool volume

Stool Lactic $\quad$ FIG. 2. Mean daily stool volume, lactic acid, and volatile fatty acids in case 12 , showing response to carbohydrate withdrawal. 

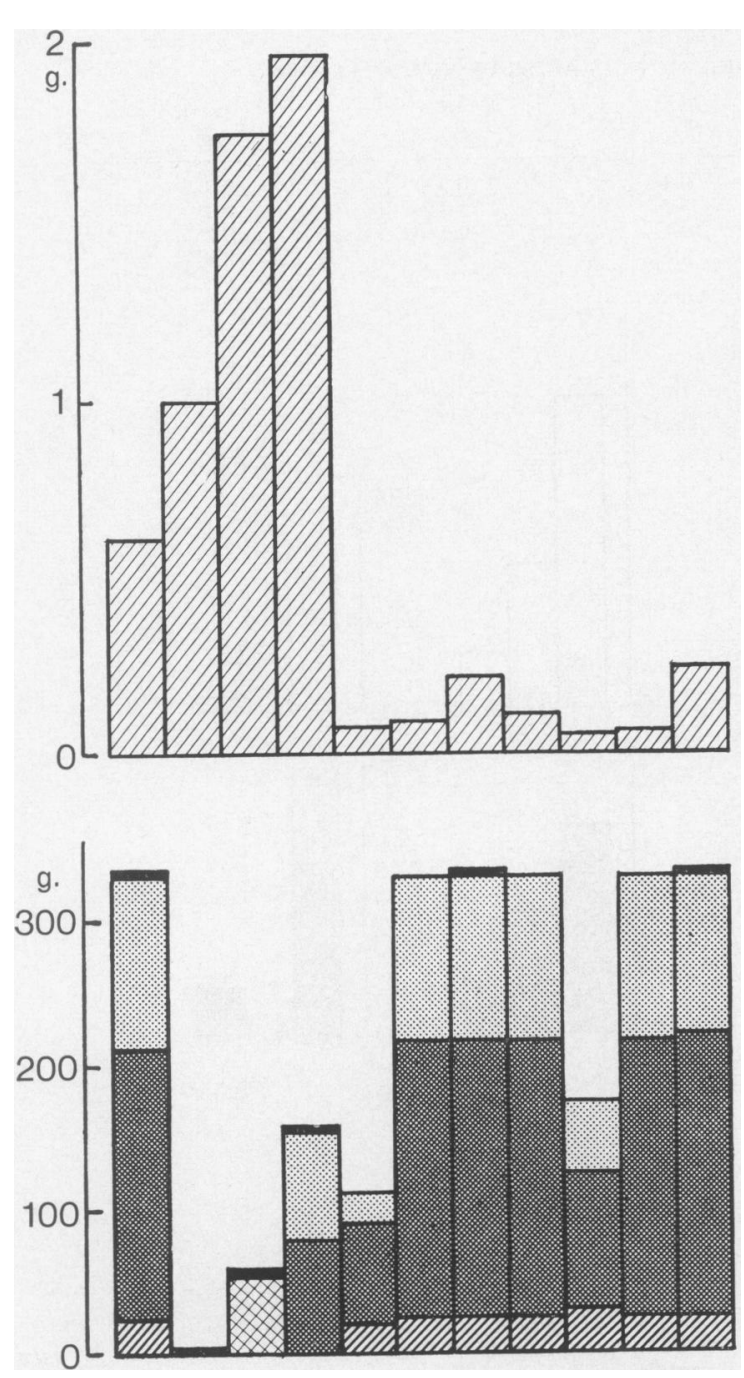

FIG. 3. The effect of dietary carbohydrate on mean daily stool lactic acid in case 20 , showing the specific effect of cellulose in this patient (see Fig. 2 for key).

be demonstrated by these organisms either in separate or combined cultures. No other cases have shown a similar reaction to cellulose.

Tests of various combinations of carbohydrate were made on a healthy ileostomy subject. Results are summarized in Figure 4. A striking increase in the lactic acid content of ileostomy fluid resulted from the addition of $75 \mathrm{~g}$ of lactose to his diet, whereas glucose had little or no effect. A lactosefree diet then produced a considerable reduction in the lactic acid excretion compared with the original figures on a normal home diet. In contrast to the findings in the faeces of colitis patients, these changes in lactic acid were not accompanied by any significant change in the volume of ileostomy fluid. The changes in VFA excretion were not obviously significant.

\section{DISCUSSION}

The evidence of a high incidence of small bowel disorder in severe ulcerative colitis is in agreement with that of Salem and Truelove (1965). As in their cases, the disorder seems to depend on the severity of colitis at the time of study, rather than on the duration of the history.

Increased excretion of lactic acid in the stools is also confined to moderate or severe colitis, but it is an inconstant finding, being occasionally absent in severe cases. In patients with severe steatorrhoea due to primary small bowel disorder the excretion of VFA may equal that seen in colitis, but in our experience no such cases have excreted such large quantities of lactic acid as may be found in colitis. This is illustrated in Fig. 5, where the findings in severe colitis are compared with those of patients with steatorrhoea due to Crohn's disease or gluteninduced enteropathy.

The volatile fatty acids include butyric acid, which may partly arise from the degradation of fat. However the bulk of VFA, at least in normal children, consists of acetic and propionic acids which are products of carbohydrate fermentation, as is lactic acid (Weijers and van de Kamer, 1965). Our findings therefore imply either an abnormal degree of fermentation somewhere in the intestinal tract, or a failure to absorb the products of a 'normal' degree of fermentation. We do not know what this normal is. A healthy subject with an ileostomy does not necessarily produce normal ileal fluid, since there is abnormal bacterial colonization of the lower ileum. However, the results in our ileostomy subject suggest at least that significant amounts of unabsorbed carbohydrate normally reach the lower ileum sufficient to yield as much lactic acid by fermentation as is found in colitis patients, whether the fermentation occurs in the large or small bowel. Therefore the increased stool lactic acid and VFA excretion in colitis patients could be entirely due to failure of absorption from the colon. Harris and Shields (1967) have demonstrated impaired colonic absorption of electrolytes and water in total colitis but not in distal colitis, and the same may be expected with regard to other solutes.

Although some patients may show disaccharidase deficiency, this is not a constant feature; the only prerequisites appear to be extensive disease of the colon and the presence of fermenting flora in the 


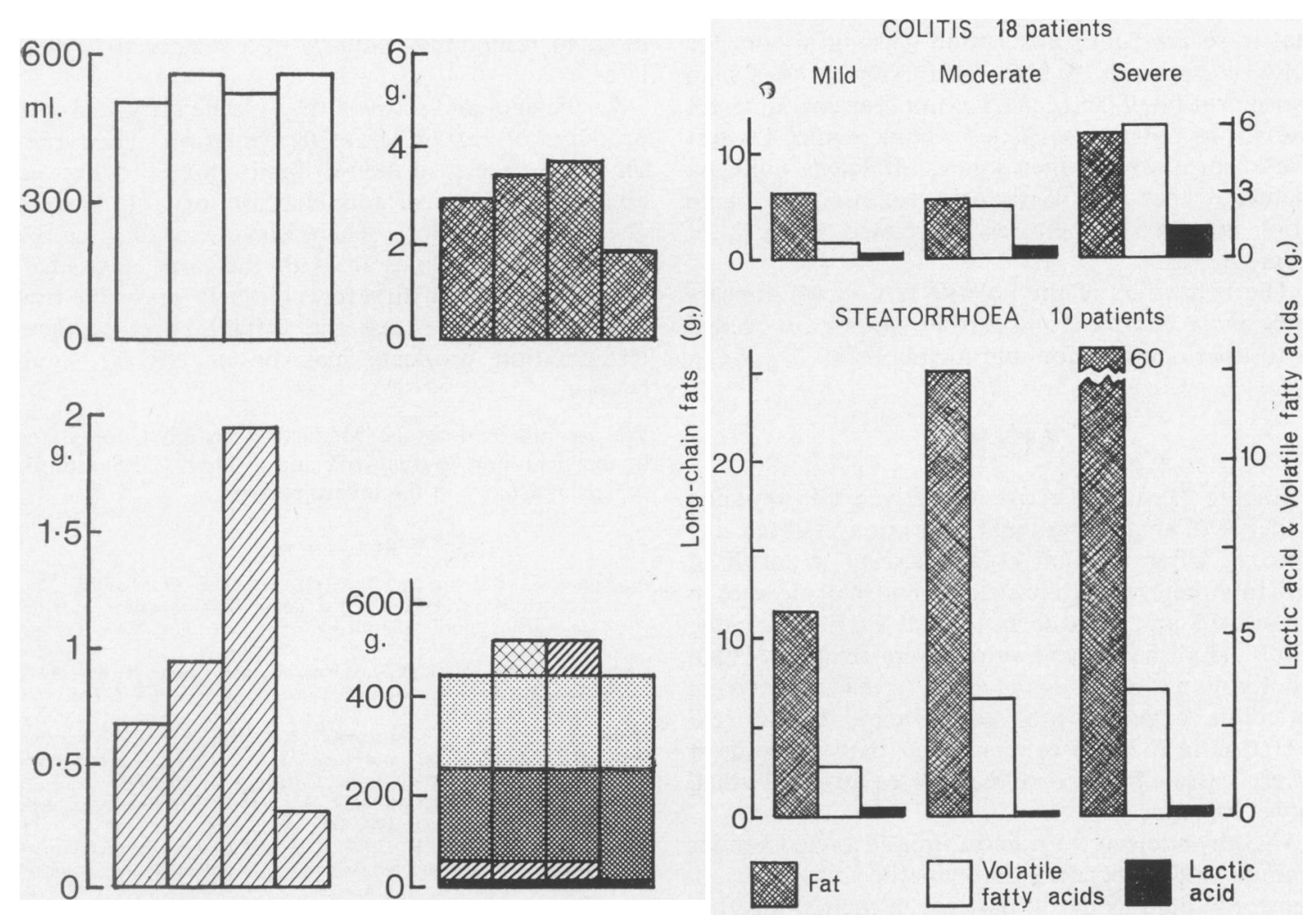

FIG. 4.

FIG. 5 .

FIG. 4. The effect of dietary carbohydrates on the mean daily volume, lactic acid excretion, and VFA excretion in ileostomy fluid in a healthy ileostomy subject, showing the relation of lactic acid excretion to lactose intake, without change in volume.

The intervals on the abscissae in Figs. 2, 3, and 4 represent variable time intervals of from four to 12 days (see Fig. 2 for key).

FIG. 5. Mean stool content of long-chain fats, lactic acid, and VFA in ulcerative colitis (18 cases) compared with cases of steatorrhoea due to gluten-induced enteropathy or Crohn's disease (10 cases).

bowel lumen. It is reasonable to suppose, however, that patients with enzyme deficiency would tend to produce more florid intestinal fermentation.

Lactase deficiency may be an inherent defect, or may arise as a non-specific result of mucosal damage. In our series there appeared to be one example of each. In only two of our 11 cases of jejunal biopsy did we consider that the structural changes were clearly pathological. Newcomer and McGill (1967) found no evidence of mucosal damage or of reduced disaccharidase activity at the level of the ligament of Treitz in cases of active ulcerative colitis compared with controls. On the other hand, Cady, Rhodes, Littman, and Crane (1967) found lactase deficiency in $46 \%$ of cases of ulcerative colitis. Dietary tests showed that, whereas colitis patients with the deficiency showed a specific diarrhoeal response to a $100 \mathrm{~g}$ dose of lactose, and tended to react adversely to milk, the effect of divided doses of either lactose or glucose was indistinguishable. and was unrelated to the enzyme levels.

Most of our patients with very high lactic acid excretion in the stools showed prompt clinical improvement on withdrawal of carbohydrate from the diet. As previously suggested (Frazer et al, 1966) this might be due not only to the osmotic effect of lactic acid and VFA but to their irritant effect on already damaged mucosa. Propionic and butyric acid are irritants of the small bowel mucosa in the rat, producing inflammatory changes and excessive mucus secretion (Schneider, 1968). The osmotic effect of lactic acid is illustrated by the correlation with stool volume (Fig. 1); and the fact that in a healthy ileostomy subject changes in lactic acid are not accompanied by corresponding changes in the volume of ileostomy fluid is further evidence 
that in severe colitis absorption of solutes from the colon is impaired. A low stool volume with a high concentration of lactic acid has not been encountered, and for osmotic reasons this would require a selective absorption of other solutes. It seems unlikely, therefore, that high lactic acid excretion and large stool volumes are entirely unrelated features of severe colitis.

The behaviour of the volatile fatty acids appears to be more complex, and further studies are needed as to their composition and metabolism.

\section{SUMMARY}

Studies in 23 cases of active ulcerative colitis revealed evidence of small bowel malabsorption in about one third of cases of total colitis. Except in localized proctitis there was a consistent abnormal increase in lactic acid and volatile fatty acid excretion in the stools. High lactic acid values were related to high stool volumes and the highest lactic acid values were in colitis patients with steatorrhoea. Lactic acid excretion in these cases was higher than in the most severe cases of steatorrhoea due to primary small bowel disease.

Healthy subjects with ileostomies excreted similar amounts of lactic acid and volatile fatty acids in ileostomy fluid as did ill patients in their stools, but fat excretion was normal. The lactic acid excretion of an ileostomy subject was directly related to the lactose content of the diet, but there were no corresponding changes in the volume of ileal fluid.

In seven out of 12 cases of active colitis drastic removal of sugars and starch from the diet led to a fall in lactic acid excretion and in stool volume to normal or near normal levels, and four of these patients achieved a lasting clinical remission. One of them responded similarly in a relapse two years later.

Lactic acid and most of the volatile fatty acids are products of carbohydrate fermentation. Their presence in excess in bowel fluid implies either an abnormal degree of fermentation or a failure to absorb them, or both. There is evidence of impaired absorption of solutes in both the large and small bowel in patients with severe colitis. It is possible that when present in excess the irritant effect of these fermentation products may be of clinical significance.

We are indebted to the Medical Research Council for financial support in this work and to Dr H. G. Sammons for his assistance in the investigations.

\section{REFERENCES}

Auricchio, S., Rubino, A., Tosi, R., Semenza. G., Landolt, M. Kistler, H., and Prader, A. (1963). Disaccharidase activities in human intestinal mucosa. Enzymol. Biol. Clin. (Basel), 3, 193-208.

Cady, A. B., Rhodes, J. B., Littman, A., and Crane, R. K. (1967). Significance of lactase deficit in ulcerative colitis. J. Lab. clin. Med., 70, 279-286.

Frazer, A. C., Hood, C., Montgomery, R. D., Davies, A. G., Schneider, R., Carter, P. A., and Goodhart, J. (1966). Carbohydrate intolerance in ulcerative colitis. Lancet, 1, 503-505.

Friedemann, T. E., and Greeser, J. B. (1933). Determination of lactic acid. J. Biol. Chem., 100, 291.

Harris, J., and Shields, R. (1967). The absorption and secretion of water, sodium and potassium by the intact human colon in ulcerative colitis., Gut, 8, 633.

van de Kamer, J. H., ten Bokkel Huinink, H., and Weijers, H. A. (1949). Rapid method for determination of fat in feces. J. biol. Chem., 177, 347-355.

Newcomer, A. D., and McGill, D. B. (1967). Incidence of lactase deficiency in ulcerative colitis. Gastroenterology, 53, 890-893.

Salem, S. N., and Truelove, S. C. (1965). Small-intestinal and gastric abnormalities in ulcerative colitis. Brit. med. J., 1, 827-831.

Sammons, H. G., Morgan, D. B., Frazer, A. C., Montgomery, R. D. Philip, W. M., and Phillips, M. J. (1967). Modification in the xylose absorption test as an index of intestinal function. Gut, 8, 348-353.

Schneider, R. (1968). Unpublished data.

Weijers, H. A., and van de Kamer, J. H. (1965). Treatment of malabsorption of carbohydrates. Mod. Treat., 2, 378-390. 